\title{
Preliminary Phytochemical Analysis And Antimicrobial Activty Of Andrographis Serphyllifolia - (Rottler ex Vahl) Wight: Acanthaceae
}

\author{
Vadivalagan $A^{1}$, Kannan. $R^{2}$, V. Balasubramaniam ${ }^{3}$ \\ ${ }^{1,2}$ Dept. of Botany, Chikkaiah Naicker College, Erode-638004, Tamil Nadu, India \\ ${ }^{3}$ Dept. of Botany, Kongunadu Arts and Science College (Autonomous), Coimbatore-641029, Tamilnadu, India \\ Corresponding author: vadivalagan.guru@gmail.com
}

Available online at: www.isroset.org

Received: 18/Jul/2019, Accepted: 02/Aug/2019, Online: 31/Aug/2019

\begin{abstract}
Andrographis serpyllifolia (Rottler ex Vahl) Wight, belonging to Acanthaceae family known for its ethnobotanical importance and possess anti- venom potential especially for snake and scorpion bites. The present study is focused to evaluate the phytochemical profiles and antimicrobial activity A. serpyllifolia using petroleum ether, acetone and methanol solvents. The results revealed that presence of alkaloids, flavonoids, saponins, phenols, steroids, glycosides, tannins and resins in various extracts studied. Antibacterial activity of A. serpyllifolia against Gram negative bacterial strains Serratia marcescens and Escherichia coli showed $6 \mathrm{~mm}$ and $9 \mathrm{~mm}$ zone of inhibition respectively in 50\% concentration of extracts studied. Antifungal activity of petroleum ether extract showed highest zone of inhibition $(11 \mathrm{~mm})$ against Penicillium notatum and Fusarium oxysporum at $100 \%$ concentration.
\end{abstract}

Keywords: Andrographis serpyllifolia, phytochemical screening and anti-microbial activity.

\section{INTRODUCTION}

Plants have been an important source of medicine for thousands of years. Even today, the World Health Organization (WHO) reports that about $80 \%$ of the World's population depends on traditional medicines to meet at least some of their primary healthcare [1]. Thus, medicinal plants are under tremendous pressure all across the globe, especially in India. More than 90\% of the medicinal plants for herbal industries in India for export are drawn from the natural habitats thus challenging their existence [2,3]. India is enormously rich in its plant wealth. It is estimated that over 15,000 species of higher plants occur in different phyto-geological/ecological regions of the country, in which about one third are economically important. Among the various kinds of plants, food plants received the earliest attention of mankind and reflect man's search for knowing more and more about their nutrient qualities [4].

Andrographis serpyllifolia (Rottler ex Vahl) Wight, a member of the family Acanthaceae, is one of the preeminent medicinal plant beside with A. paniculata with substantial benefits. The habit of A. serpyllifolia does not similar to A. paniculata but possesses immense activity and used in several ethnobotanical formulations. It has the record for successfully surviving multiple geo-ecological challenges and grazing threats. It is endemic to the arid southern Indian peninsular states. Thoroughgoing investigators have focused only on phytochemistry and pharmacological activity of this plant [5]. It is a trailing and rooting procumbent herb widely distributed throughout South India and investigated for its ethnomedicinal properties [6]. It is erect herb and whole plant extract used orally administrated for snake bite, dog bite and fever like malaria and typhoid [8]. The present study aimed to investigate phytochemical and antimicrobial activity different extract of A. serpyllifolia.

\section{MATERIALS AND METHODS}

\section{Preparation of extracts}

The whole plants were collected and shade dried for about two weeks and ground into coarse powder. About $80 \mathrm{~g}$ powder of plant was extracted with $125 \mathrm{ml}$ of petroleum ether using soxhlet apparatus. The same powders were also extracted with acetone and methanol. The extracts were concentrated to dryness to yield crude residue. These residues were used for preliminary phytochemical screening of secondary metabolites and also subjected to antimicrobial testing. 


\title{
III. PRELIMINARY PHYTOCHEMICAL SCREENING
}

In the present study, all preliminary phytochemical screening was carried out following the methodology of [9].

\begin{abstract}
Alkaloids
Meyer's reagent (potassium mercuric iodide)

$1.36 \mathrm{gm}$ of mercuric chloride was dissolved in $60 \mathrm{ml}$ of distilled water and $5 \mathrm{gm}$ of potassium iodide was dissolved in $10 \mathrm{ml}$ of water. These two solutions were mixed and diluted to $100 \mathrm{ml}$ with distilled water. To $1 \mathrm{ml}$ of the extract, a few drops of reagent were added. Formation of white or pale precipitate showed the presence of alkaloids.
\end{abstract}

\section{Flavonoids}

In test tube containing $0.5 \mathrm{ml}$ of extract, 5 to 10 drops diluted $\mathrm{HCl}$ and small piece of $\mathrm{ZnCl}$ or magnesium were added and the solution was boiled for few minutes. The appearance of reddish pink or dirty brown colour indicates the presence of flavonoids.

\section{Saponins}

In a test tube containing about $5 \mathrm{ml}$ of the extract, few drops of sodium bicarbonate was added. The mixture was shaken vigorously and kept for 3 minutes. A honeycomb like froth was formed and it showed the presence of saponins.

\section{Glycosides}

A small amount of extract was dissolved in $1 \mathrm{ml}$ of water and aqueous sodium hydroxide solution was added. Formation of yellow colour indicates the presence of glycosides.

\section{Steroids}

To $2.0 \mathrm{ml}$ of extract, $1.0 \mathrm{ml}$ of concentrated sulphuric acid was added carefully along the sides of the test tube. A red colour produced in the chloroform layer shows the presence of steroids.

\section{Resins}

To $2.0 \mathrm{ml}$ of extract $5.20 \mathrm{ml}$ of acetic anhydride was added, dissolved by gently heating, cooling and then $0.5 \mathrm{ml}$ of sulphuric acid was added. Bright purple colour indicates the presence of resins.

\section{Phenols}

Ferric chloride test:

To $1 \mathrm{ml}$ of the extract $3 \mathrm{ml}$ of distilled water followed by few drops of $10 \%$ aqueous Ferric chloride solution was added. Formation of blue or green colour indicates the presence of phenols.

\section{Tannins}

Lead acetate test: In a test tube containing about $5 \mathrm{ml}$ of the extract, a few drops of $1 \%$ solution of lead acetate was added. A yellow or red precipitate indicates the presence of tannins.

\section{ANTIMICROBIAL ACTIVITY}

The bacterial and fungal strains were obtained from the Department of Microbiology, KMCH Hospitals, Coimbatore, Tamilnadu. The bacterial strains were maintained in nutrient agar slants and fungal strains in potato dextrose agar slants. Antibacterial and Antifungal studies were carried out by Disc Diffusion methods. The gram negative bacterial strains Serratia marcescens and Escherichia coli, fungal strains Penicillium notatum and Fusarium oxysporum were used as testing organism.

\section{Preparation of Culture Medium and Inoculation}

The Petri plates and the nutrient agar medium as well as potato dextrose medium were sterilized for 20 minutes at $120^{\circ} \mathrm{C}$. The rest of the procedure was carried out in laminar air flow. Approximately $20 \mathrm{ml}$ of the media was poured into the sterile Petri plates and allowed to get solidify for 15-20 minutes. After the media gets solidified, the bacterial and fungal organisms were swabbed in respective medium using cotton swabs.

\section{Disc Diffusion method}

Antimicrobial activity of the plant extracts were tested using the disc diffusion method according to [10]. Sterile nutrient agar plates and potato dextrose plates were prepared for bacterial and fungal strains respectively and inoculated by a spread plate 
method under aseptic conditions. The filter paper discs of $6 \mathrm{~mm}$ diameter (What man's No. 1 filter paper) were prepared and sterilized. The plant extracts to be tested were prepared with various concentrations of $25 \mathrm{mg} / \mathrm{ml}, 50 \mathrm{mg} / \mathrm{ml}, 75 \mathrm{mg} / \mathrm{ml}$ and 100 $\mathrm{mg} / \mathrm{ml}$ and were added to each disc of holding capacity of 10 microlitres. The sterile impregnated disc with plant extracts were placed on the agar surface with framed forceps and gently pressed down to ensure complete contact of the disc with the agar surface. Control discs were also placed using respective solvents used for the extraction. All the plates including control plates were incubated at $37^{\circ} \mathrm{C}$ for 24 hours. After incubation, the sizes (diameter) of the inhibition zones were measured.

\section{RESULTS AND DISCUSSION}

Adopting the methods of [9] the Petroleum ether, Acetone, Methanol extracts were tested for the presence phytochemical constituents in the study plant species. In the present study phytochemical screening the whole plant of A. serpyllifolia showed the presence of alkaloids, flavonoids, saponins, phenols, steroids, glycosides, tannins and resins (Table 1). Several researchers have evaluated Andrographis serpyllifolia for its phytochemical constituents both qualitative and the quantitative estimation using various type of polar and non-polar solvent system. The results revealed the presence of alkaloid, tannins, steroids, terpenoids, phlobatannin, anthraquinones, flavonoids, saponins and phenolic compounds in qualitative analysis [5]. Quantitative analysis showed the presence of saponins and tannins in high quantity followed by phenolic compounds, alkaloids and flavonoids [11]. The phytochemical screening of methanol extract of leaves of A. serpyllifolia revealed the presence of sterols, cardiac glycosides, saponins, flavonoids, tannins and phenols [12].

Table 1. Preliminary phytochemical analysis of various extracts of Andrographis serpyllifolia.

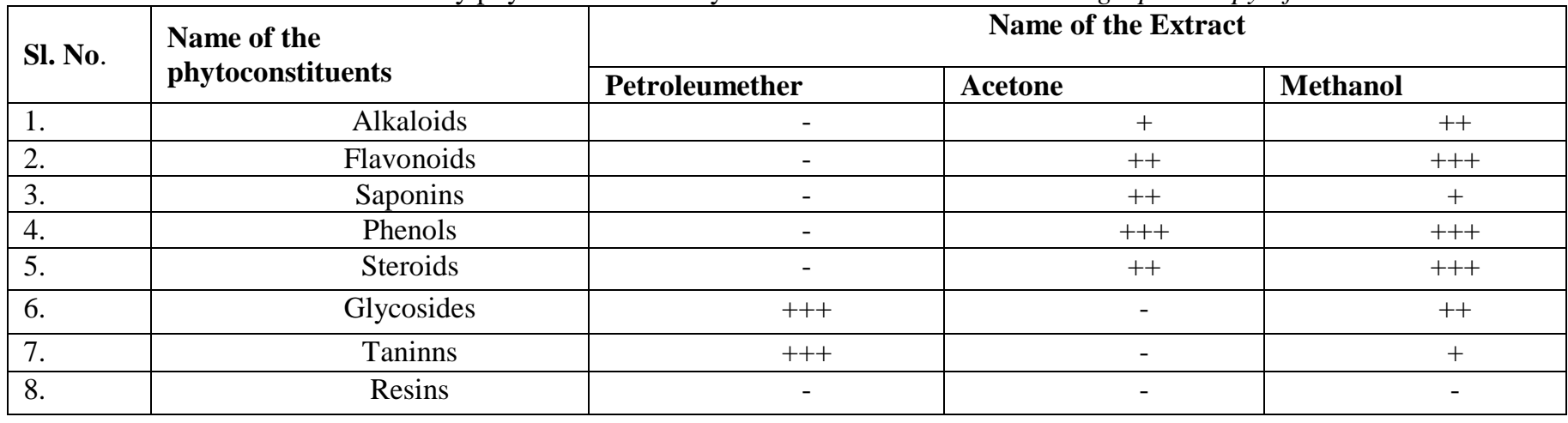

The results revealed that the $50 \%$ concentration of all the extracts of A. serpyllifolia showed $6 \mathrm{~mm}$ zone of inhibition against $S$. marcescens, $50 \%$ methanol extract registered highest zone of inhibition $(9 \mathrm{~mm})$ against E. coli. The result clearly indicated that the tested bacteria were highly susceptible for $50 \%$ concentration of the extracts of A. serpyllifolia (Table 2). Antimicrobial activity of Andrographis paniculata extracts against some human pathogens. The results exhibited that the extracts of $A$. paniculata did not show any antibacterial activity against the seven pathogens [13]. However higher concentration of the extracts showed positive activity against two of the selected pathogens, Legionella pneumophila and Bordetella pertussis.

Table 2. Antibacterial activity whole plant different extracts of Andrographi sserpyllifolia against Serratia marcescens and Escherichia coli.

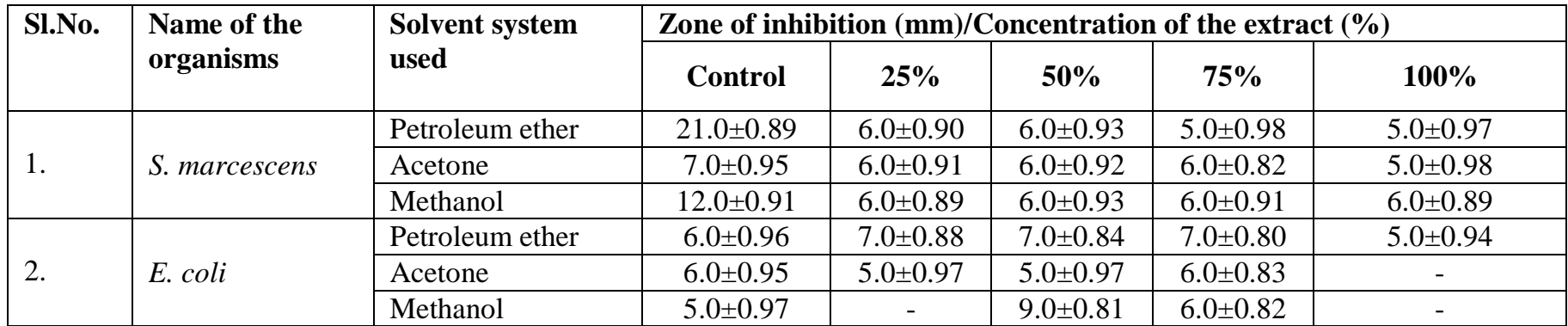

Values are mean \pm SD $(n=3)$; Mean values followed by different superscripts in a column are significantly different $(P<0.05)$ according to Duncan's multiple range tests (DMRT). 
The current findings indicated that antifungal activity of petroleum ether extract showed highest of $12 \mathrm{~mm}$ zone of inhibition in methanol extract at $25 \%$ concentration followed by $11 \mathrm{~mm}$ zone of inhibition at $100 \%$ concentration in petroleum ether and methanol against Penicillium notatum and Fusarium oxysporum showed moderate activity in petroleum ether and methanol. The other extract acetone did not show any inhibition zone against both the organisms studied (Table.3). The antimicrobial activity reported in A. serpyllifolia may be due to the presence of glycosides, alkaloids, saponin, steroids, tannins and terpenes. The methanol extracts of the plant showed moderate activity against Staphylococcus aureus, Salmonella typhii and Xanthomonas oryzae indicating a broad spectrum activity [12].

The experiment on Sprague-Dawleyrats infected with Salmonella typhii was treated with ethanol leaves extract of A. serpyllifolia studies showed that A. serpyllifolia possess antimicrobial activity against $S$. typhii and could be indorsed for clinical trials for the treatment of typhoid[7].The antibacterial activity of A. serpyllifolia leaf and stem extracts (acetone and aqueous) was carried out against four human pathogenic bacterial species viz., Bacillus cereus, Staphylococcus aureus, Escherichia coli and Klebsiella pneumonia by agar well diffusion method by Alageshaboopathi [8,14]. The investigation shown that aqueous stem extract and acetone extract of leaf and stem showed significant activity against Gram positive bacteria such as Bacillus cereus, Staphylococcus aureus and moderate activity against Gram negative bacteria like Escherichia coli, Klebsiella pneumoniae compared to standard drug Ciprofloxacin. The stem extract showed a higher inhibitory effect than the leaf extracts.

Table 3. Antifungal activity whole plant different extracts of Andrographis serpyllifolia against Penicillium notatum and Fusarium oxyporum.

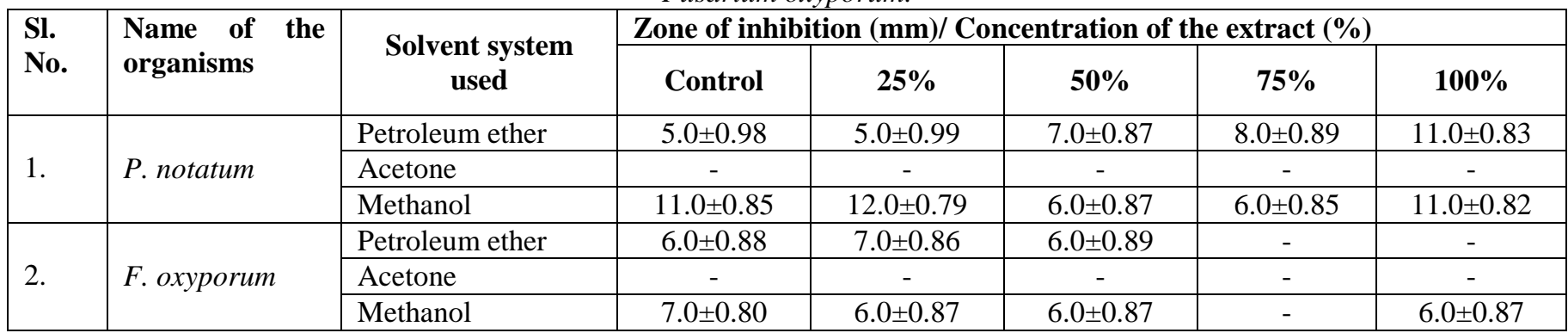

Values are mean \pm SD $(n=3)$; Mean values followed by different superscripts in a column are significantly different $(P<0.05)$ according to Duncan's multiple range tests (DMRT).

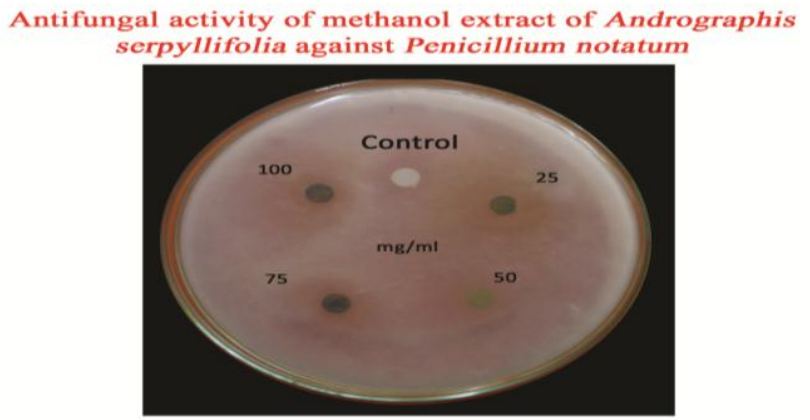

Antifungal activity of Pet. Ether extract of Andrographis serpyllifolia against Fusarium oxysporum

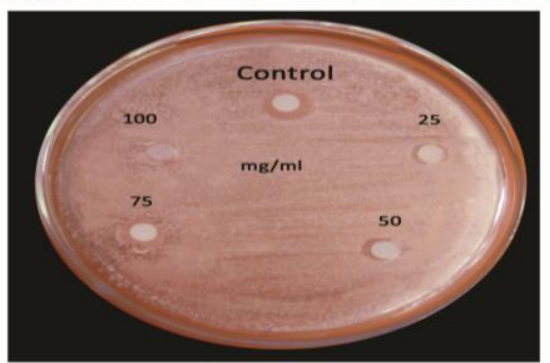

Figure 1. Shows the inhibition of crude extract of Andrographis serpyllifolia against fungal pathogens. 


\section{REFERENCES}

[1]. WHO. Legal Status of Traditional Medicine and Complementary/Alternative medicine: A world wide review. WHO Publishing, 2001.

[2]. J. Hussain, A.L. Khan, N. Rehman, M. Hamayun, Z.K. Shinwari, W. Ullah, I.J. Lee, "Assessment of herbal products and their composite medicinal plants through proximate and micronutrients analyses", Journal of Medicinal Plants Research, Vol.3,Issue.12, pp. 1072-1077, 2009.

[3]. Fazal, N. Ahmad, B.H. Abbasi, N. Abbass, "Selected medicinal plants used in herbal industries; their toxicity against pathogenic microoraganisms”, Pak. J. Bot., Vol.44, Issue. 3, pp. 1103-1109, 2012.

[4]. S.K. Jain, "Glimpses of Indian Ethno botany. Oxford \& IBH Publishing Co., New Delhi, India, 1981

[5]. S. Krishnaswamy, B.A. Kushalappa, "Systematic Review of Andrographis serpyllifolia (Rottler ex Vahl) Wight: An Ethno-pharmaco-botanical Perspective. Pharmacog J. Vol.10, Issue.6, Suppl., pp.S14-S26, 2018.

[6]. P. Samydurai, A. Rajendran, A. Sarvalingam, C. Rajasekar, "Ethnobotanical knowledge of threatened plant species of Andrographis in Nilgiris Biosphere Reserve, Tamilnadu, India”, International Journal of Herbal medicine, Vol.5, Issue.6, pp.103-107, 2017.

[7]. M.G. Panduranga, K.B. Chandrasekhar, B.C. Leelaja, S. Lokesh, "Antimicrobial and Antioxidant Activities of Tribal Medicine formulation (TMF) accomplished for Wound related remedies in Biligirirangana Hill area of Chamarajanagara district, Karnataka (India), IJPC., Vol.5, Issue. 8, pp.260-276, 2015.

[8]. C. Alageshaboopathi, "Ethnobotanical Studies on useful Plants of Kanjamalai Hills of Salem district of Tamil Nadu, Southern India", Archives of Applied Science Research, Vol. 3, Issue.5, pp.532-539, 2011.

[9]. J.B. Harborne, "Phytochemical Methods, Chapman and Hall, Ltd"., London, pp. 49-188.1973

[10]. A.W. Bauer, W.M.M. Kirby, J.C. Sherris, M. Turck, “Antibiotic susceptibility testing

[11]. by a standardized single disk method", Amer. I. C/in. Pathol., Vol.45, pp.493-6,1966.

[12]. [Depts. Microbiology and Medicine, Univ. Washington, Sch. Med., Seattle. WAI]

[13]. K. Narasimhamurthy, "Phytochemical screening and In vitro assessment of antimicrobial and antioxidant potential of Andrographis serpyllifolia - An endemic medicinal plant from South India", International Journal of Advanced Research, Vol.2, Issue.2, pp. 917-928, 2014.

[14]. R.J.B.A. Ravishankar, V.S. Pradeepa, "Evaluation of the antimicrobial activity of three medicinal plants of South India", Malaysian Journal of Microbiology, Vol.7, Issue. 1,pp.14-21.2011

[15]. Y. Xu, R.L. Marshall, T.K.S. Mukkur, "An investigation on the antimicrobial activity of Andrographis paniculata extracts and Andrographolide in vitro", Asian. J. Plant. Sci., Vol.5, pp.527-530. 2006

[16]. C. Alagesaboopathi, "Screening of antibacterial potential of leaves and stem extracts of Andrographis serpyllifolia (Vahl) Wight - An endemic medicinal plant of India", Journal of Pharmacy Research, Vol.5, Issue 12, pp. 5404-5407, 2012. 